\title{
Improving tauG-control of action in PD
}

\author{
Benjaman Schögler \\ University of Edinburgh \\ Rachel Polokoff \\ University of Edinburgh \\ Gert-Jan Pepping \\ Australian Catholic University \\ Jon Perkins \\ University of Edinburgh \\ David N Lee \\ University of Edinburgh
}

\begin{abstract}
A theory of action control (General Tau Theory) is applied to analyzing normal and abnormal movements in PD; and to designing and testing the efficacy of a sonic aid for PD. A central aspect of the theory, which is supported by experimental evidence across a variety of actions and species, is that the trajectories of competent skilled actions follow a particular temporal pattern, which is described by the mathematical function, tauG. Since tauG-control of actions can be largely deficient in PD, we designed a device that generates whoop-like sounds, where the fundamental frequency of the sound follows the tauG pattern. Our hypothesis was that by listening to these sounds the nervous system of someone with PD might be helped subsequently to self-generate tauG patterns in their nervous system, which might facilitate movement control in different situations. Five adults with PD, and five age-matched controls, took part in the study. They each listened to the sounds under two conditions: (a) experimental - turning a handle for 5 minutes while the sounds were played (b) control - turning the handle without the sounds. Before and after each condition, the tauG-control of lateral body sway while standing was measured (without the sounds playing), using force-plates, on two tasks: (i) keeping the feet down, (ii) lifting the trailing foot. The number of participants out of five, who showed greater ratio improvement following practice with whoop sounds compared to without sounds, was, on each task, high for the PDs compared with the agematched controls (4 vs 2 or 3). Thus, for the PDs, listening to the tauG whoop-like sounds while performing one action (handle turning) improved subsequent tauG-control on a different task (body-swaying).
\end{abstract}


bioRxiv preprint doi: https://doi.org/10.1101/143313; this version posted May 28, 2017. The copyright holder for this preprint (which was not certified by peer review) is the author/funder, who has granted bioRxiv a license to display the preprint in perpetuity. It is made available under aCC-BY-ND 4.0 International license.

\section{Introduction}

Parkinson's disease (PD) is a neural disorder that predominantly affects a person's ability to execute purposeful movement (Marsden, 1994). Most common activities, like walking, writing, speaking, looking, reaching, grasping, and holding a limb still can be affected. It is generally considered that disorders in the basal ganglia play a central role in the disease - in particular, that death of dopaminergic neurons in the substantia nigra pars compacta depletes the vital supply of the neurotransmitter, dopamine, to brain cells. Consequently, symptoms of PD are mainly managed through prescribed medication (levadopa) to augment the depleted dopamine supply. However, the positive effects of the treatment are off-set by a reduced response over prolonged treatment and increasing negative side effects, such as dyskinesia, with increased dosage (Fahn, 1996). After several years many patients may experience crippling 'on/off' phenomena defined by Marsden as "sudden and unpredictable fluctuations in motor disability unrelated to the timing of levadopa intake" (Marsden, 1994 p.675). It is not clear to what extent increased motor dysfunction and dyskinesias in PD are due to the natural progression of the disease or to prolonged exposure to levadopa therapy (Fahn, 1996). As life expectancy is near normal for patients, the question of when to prescribe levadopa to alleviate the symptoms of PD is a complex one, but on the whole recommendations are for delaying such treatment until absolutely necessary (Marsden, 1994). As a consequence supplementary methods of improving or sustaining mobility are a key concern in both the treatment and management of the disease. However, the precise neural functions that are disabled in Parkinson's disease, leading to poor control of purposeful movement, has remained a mystery, which means that satisfactory treatment of the disease has remained elusive. In this paper we address the neural basis of Parkinson's disease, and then develop and test a non-invasive method for alleviating the neuromotor symptoms of the disease.

We start by considering the three basic functions of the nervous system that are normally involved in effective control of purposeful actions. These are prescribing the action, perceptually monitoring the action, and performing the action. Consider, for example, piano playing. The musical actions on the keys must be prescribed in the pianist's nervous system, because it is the pianist who determines what to play and how to play it. The pianist's nervous system must also perceptually monitor the musical actions as they unfold, because external forces (such as sticky keys) can knock actions off their intended course. Finally the pianist's nervous system has to press the keys appropriately so that the perceptually monitored actions match the prescribed actions.

Given that these three basic functions of the nervous system - prescribing, perceptually monitoring and performing - are the foundation of all purposive actions, the question arises: which of these functions are compromised in PD? The phenomenon of paradoxical movement provides a clue (Martin !967; Glickstein \& Stein, 1991; Majsak et al., 1998). Someone suffering from 
Parkinson's disease may find it difficult to reach out for a stationary ball, for instance, but is able to catch a moving ball with comparative ease. Or they may experience difficulty walking across a clear floor, yet can step out relatively easily when going up or down stairs. The phenomenon of paradoxical movement suggests that it is the prescriptive function of the nervous system that is principally impaired in Parkinson's disease, rather than the perceptual monitoring or the performing functions, because the latter two functions are clearly operating well when carrying out paradoxical movements, like catching a ball or walking down stairs.

What, precisely, is the prescriptive function of the nervous system that might be impaired in Parkinson's Disease? According to General Tau Theory (Lee 1998, 2009), which is a general theory of action control inspired by the pioneering theories of Gibson (1966) and Bernstein (1967), one way of prescribing how an action-gap should close is to make the tau of the gap (the time to closure of the gap at the current rate of closure) proportional to a particular tau function, called tauG, which equals the tau of a gap that closes from rest at constant acceleration - as when Newton's apple fell to the ground. The mathematical formula for tauG, $\tau_{G}=\frac{1}{2}\left(t-T_{G}^{2} / t\right)$, is, appropriately enough, derived from Newton's equations of motion, where $T_{G}$ is the time to closure of the $G$ gap and time, t, runs from zero to $T_{G}$. The tauG-control equation describing the prescribed manner of closure of an action-gap, $X$, is

$$
\tau_{X}=\frac{1}{2} k\left(t-T_{G}^{2} / t\right)
$$

where $\tau_{X}$ is the tau of gap $X$, and $k$ is a coupling constant which determines how gap $X$ is prescribed to close - gently, ending with zero velocity, if $k \leq \frac{1}{2}$; or forcefully, ending with positive velocity, if $k>\frac{1}{2}$.

There is experimental behavioural evidence across a range of activities and species that tauG $\left(\tau_{G}\right.$ ) is used in controlling purposeful movements (Lee 2009). There is also neural evidence that tauG is generated in the nervous system. Electrical activity of tauG form has been recorded in globus pallidus in the basal ganglia of monkeys reaching to targets (Lee et al., 2017a). In general, the experiments indicated that globus pallidus is involved in prescribing the movement, the subthalamic nucleus is involved in perceptually monitoring the movement, and zona incerta is involved in performing the movement, by integrating the prescribing activity of globus pallidus and the perceptually monitoring activity of the subthalamic nucleus to power the muscles to perform the movement. In all cases the neural information took the form of the relative-rate-of-change $(=1 / \tau)$ of the flow of electrochemical energy in neurons, relative to a reference level. 
Our behavioural and neural findings, together with the phenomenon of paradoxical movement in PD, suggested that action control might be improved in PD by stimulating the nervous system with tauG patterns. A non-invasive way of doing this is through sound. Musical sound is often a rich source of tauG patterns (Schogler, Pepping \& Lee, 2008), which is possibly why people with PD find that music helps them move more easily. To test the efficacy of sonic tauG stimulation per se in improving movement control in $\mathrm{PD}$, we designed tauG-patterned whoop-like sounds, where the fundamental frequency moved up an octave in a tauG way.

\section{Generating tauG-guided sounds}

The sounds were generated on a computer. The frequency of a sound was tauG-guided between a start frequency and an end frequency using Eq. (1), viz., $\tau_{f}=\frac{1}{2} k\left(t-T_{G}^{2} / t\right)$, where $f$ is the frequency gap to the end frequency, $T_{G}$ is the duration of the sound and time t runs from zero to $T_{G}$. Integrating this equation results in the equation $f=f_{\text {range }} T_{G}^{-k / 2}\left(T_{G}^{2}-t^{2}\right)^{1 / k}$, where $f_{\text {range }}=$ end frequency - start frequency. Thus, if a movement gap, $X$, were tau-coupled with coupling constant, $\alpha$, to the frequency-gap, $f$, then from Eq. (1), $\tau_{X}$ would equal $\frac{1}{2} k \alpha\left(t-T_{G}^{2} / t\right)$ and so gap $X$ would be $\operatorname{tau} G$-guided. In the present study, an octave frequency range was programmed, starting at 440 $\mathrm{Hz}$ (concert A). The duration, $T_{G}$, of the sound was $1.2 \mathrm{~s}$, and the coupling constant, $k$, was 0.5 . During the experiments the sounds were played to the participants from a laptop computer.

\section{Participants}

Five volunteers with PD and five healthy age-matched volunteer controls took part in the study. The Parkinson volunteers were recruited from the Lothian self-help PD group. The healthy participants either were from the University of Edinburgh or were spouses or friends of the patients. Each participant was informed about the nature of the study and signed a consent form stating that they could terminate their participation in the study at any time. The study was approved by the Ethics Committee of the School of Philosophy Psychology and Language Sciences, University of Edinburgh. A questionnaire was given to the patients to assess their Parkinson symptoms and medication (Table 1). All the patients started trials in the study when at the peak of their medication. 
bioRxiv preprint doi: https://doi.org/10.1101/143313; this version posted May 28, 2017. The copyright holder for this preprint (which was not certified by peer review) is the author/funder, who has granted bioRxiv a license to display the preprint in perpetuity. It is made available under aCC-BY-ND 4.0 International license.

Table 1 Details from PD participants' questionnaire.

\begin{tabular}{|l|l|l|l|l|l|}
\hline Participant & Gender & $\begin{array}{l}\text { Age (yrs.) } \\
\text { at testing }\end{array}$ & $\begin{array}{l}\text { Age (yrs.) } \\
\text { at diagnosis }\end{array}$ & Symptoms & Treatment \\
\hline 1 & M & 62 & 44 & $\begin{array}{l}\text { Difficulty walking, slow } \\
\text { gait, tremor, affected right } \\
\text { side. }\end{array}$ & $\begin{array}{l}\text { Deep brain stimulation } \\
\text { (at 56 yrs.). Ropinirole } \\
\text { 3 mg, 3x daily. }\end{array}$ \\
\hline 2 & M & 65 & 60 & $\begin{array}{l}\text { Slow gait, slight tremor, } \\
\text { affected left side. }\end{array}$ & Levodopa. \\
\hline 3 & M & 74 & 49 & $\begin{array}{l}\text { Difficulty walking, slow } \\
\text { gait, tremor, facial } \\
\text { freezing, slow speech, } \\
\text { affected right side. }\end{array}$ & Sinemet Plus (3x daily) \\
\hline 4 & F & 71 & 53 & $\begin{array}{l}\text { Difficulty walking, pain } \\
\text { in legs, fatigue, tremor in } \\
\text { hands, affected right side. }\end{array}$ & $\begin{array}{l}\text { Entacapone (3x daily) } \\
\text { Madopar (nightly) }\end{array}$ \\
\hline 5 & F & 68 & 47 & $\begin{array}{l}\text { Slow gait, tiny steps, } \\
\text { tremor in hands, affected } \\
\text { left side. }\end{array}$ & Levodopa. \\
\hline
\end{tabular}

\section{Recording body sway}

We studied control of lateral body sway because it is integral to maintaining balance when walking, which often poses a problem in PD. During the experiments the participant stood with their feet comfortably apart and swayed from side to side. They stood on two Kistler ${ }^{\mathrm{TM}}$ forceplates mounted in concrete in the floor of the laboratory, and the $(x, y)$ coordinates of the centre of pressure of their feet were recorded at $1000 \mathrm{~Hz}$ using a Bioware ${ }^{\mathrm{TM}}$ forceplate program.

\section{Experimental protocol}

Each participant took part in two experimental sessions, spaced about two weeks apart. Each session comprised two parts, and each part comprised three 30s tasks. The tasks are shown in Table 2. 'Sway side-to-side' means stand with the feet comfortably apart on the two forceplates and sway from side to side. 'Keep feet down' is illustrated in Fig. 1a. 'Lift trailing foot' is illustrated in Fig. 1b. 'Turn wheel' means rotate a $40 \mathrm{~cm}$ diameter wheel mounted at a comfortable height on a vertical axis on a table by means of a vertical handle mounted on the rim of the wheel. 'Turn wheel in time with heard whoops' means rotate the wheel in time with an unbroken sequence of the $1.2 \mathrm{~s}$ whoop sounds. 'Sway side-to-side with imagined whoops' means imagine whoops sounding in your head and sway in time with them. 
bioRxiv preprint doi: https://doi.org/10.1101/143313. this version posted May 28, 2017. The copyright holder for this preprint (which was not certified by peer review) is the author/funder, who has granted bioRxiv a license to display the preprint in perpetuity. It is made available under aCC-BY-ND 4.0 International license.
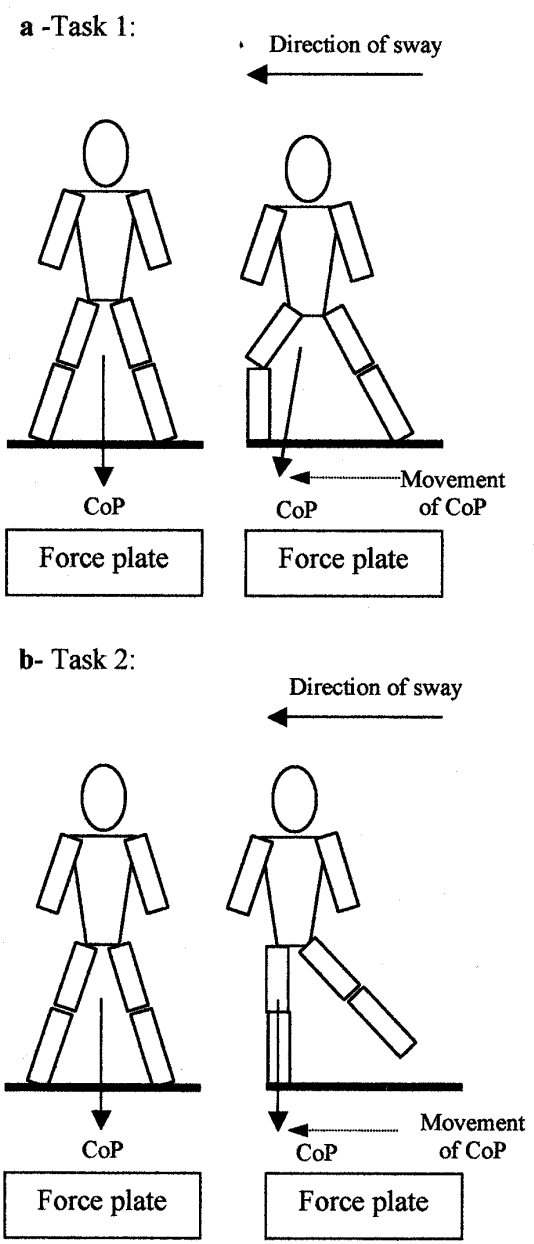

Fig. 1 (a) Task 1: sway from side-to-side without lifting feet. (b) Task 2: sway from side-to-side lifting trailing foot. 
Table 2. Experimental protocol.

\begin{tabular}{|l|l|l|}
\hline Session 1 & & \\
\hline $\begin{array}{l}\text { K1. Sway side to side. } \\
\text { C1L. Sway side to side. } \\
\text { Lift trailing foot. }\end{array}$ & Turn wheel. & $\begin{array}{l}\text { C2. Sway side to side. } \\
\text { Keep feet down. }\end{array}$ \\
\hline Session 2 & $\begin{array}{l}\text { C2L. Sway side to side. } \\
\text { Lift trailing foot. }\end{array}$ \\
\hline $\begin{array}{l}\text { C3. Sway side to side. } \\
\text { Keep feet down. }\end{array}$ & $\begin{array}{l}\text { Turn wheel in time with } \\
\text { heard 'whoop'sounds. }\end{array}$ & $\begin{array}{l}\text { C4. Sway side to side, } \\
\text { imagining the 'whoop' } \\
\text { sounds. Keep feet down. }\end{array}$ \\
\hline $\begin{array}{l}\text { C3L. Sway side to side. } \\
\text { Lift trailing foot. }\end{array}$ & $\begin{array}{l}\text { Turn wheel in time with } \\
\text { heard 'whoop' sounds. }\end{array}$ & $\begin{array}{l}\text { C4L. Sway side to side } \\
\text { imagining the 'whoop' } \\
\text { sounds. Lift trailing foot }\end{array}$ \\
\hline
\end{tabular}




\section{Measuring tauG-control of body sway}

The degree to which body sway was $\operatorname{tau} G$-controlled was measured by analyzing the movement of the centre of pressure of the feet on the force plates. Since this movement was principally in the lateral $x$-direction, the analysis was based on the changing $x$-coordinate of the centre of pressure of the feet. The $x$ time series, $\{x\}$, was analyzed using a bespoke computer program (TauServer). The program steps were as follows. (i) The $1000 \mathrm{~Hz}$ time series $\{x\}$ was smoothed with a Gaussian filter, sigma 22, to reduce noise in the data. This resulted in a time series $\left\{x_{s m}\right\}$ with a cut-off frequency of $8.3 \mathrm{~Hz}$. (ii) The $\left\{x_{s m}\right\}$ time series was numerically differentiated with respect to time to yield the velocity time series $\left\{x_{s m} v e l\right\}$. (iii) The peak values in the velocity time series, $\left\{x_{s m} v e l\right.$ \}, were found, together with the start-time, $t_{\text {start }}$, and end-time, $t_{\text {end }}$, of each particular sway movement. $t_{\text {start }}$ and $t_{\text {end }}$ were defined respectively as the times before and after the peak velocity when the velocity just exceeded $10 \%$ of the peak velocity between $t_{\text {start }}$ and $t_{\text {end }}$. This was to eliminate noisy estimates of tau when the velocity is low (since tau is the reciprocal of velocity). (iv) The values of $x_{s m}$ at times $t_{\text {start }}$ and $t_{\text {end }}$ were recorded as $x_{s m, s t a r t}$ and $x_{s m, e n d}$. (v) At each time, $t$, during each sway (for $t$ running from zero to $T$, the duration of the sway), $\tau_{X}$ was computed as $\left.\left(x_{s m}-x_{\text {sm,end }}\right) / x_{s m} v e l\right)$, and $\tau_{G}$ was computed as $\tau_{G}=\frac{1}{2}\left(t-T_{G}^{2} / t\right)$, as per Eq. (1). (vi) $\tau_{X}$ was linearly regressed recursively on $\tau_{G}$, to derive the following two measures of the degree to which closure of the gap $X\left(=x_{s m}-X_{s m, \text { end }}\right)$ was tauG-controlled. (a) The percentage of the gap that was tauG-guided, namely the highest percentage of data points up to the end of the movement that fitted the tau $G$-control equation $\tau_{G}=\frac{1}{2}\left(t-T_{G}^{2} / t\right)$, with less than $5 \%$ of the variance unaccounted for (i.e., with $r^{2}$ of the linear regression greater than 0.95 ). (b) The percentage of the variance explained by the tauG-control, which equals $100 r^{2}$. The slope of the linear regression estimates the value of the coupling constant, $k$, in the $\operatorname{tau} G$-control equation $\tau_{X}=\frac{1}{2} k\left(t-T_{G}^{2} / t\right)$.

\section{Results}

Fig. 2 shows typical records of the displacement of the centre of pressure $(\mathrm{CoP})$ when swaying sideto-side keeping feet down (Task 1), for a healthy participant (control) and an age-matched Parkinson's patient, in baseline condition C1. Figs. 2C and 2D show the displacement and velocity of the $\mathrm{CoP}$ for the single sway indicated. The vertical grey lines show the start and end points for 
the tauG analyses of the movements of the CoP towards the left. The recursive regression analysis for the control shows strong tauG-control of body sway (percentage of movement tauG-coupled $=$ $\left.100 \%, r^{2}=0.99, k=0.5\right)$, whereas the tauG-control of body sway for the Parkinson's patient is very much weaker, if it may be said to exist at all (percentage of movement tauG-coupled $=23 \%$, $\left.r^{2}=0.95, k=0.8\right)$.

Fig. 3 shows typical records of the displacement of the centre of pressure $(\mathrm{CoP})$ when swaying side-to-side lifting the trailing foot (Task 2), for a healthy participant (control) and an age-matched Parkinson's participant, in baseline condition C1L. The leftward movement is less controlled for the Parkinson's participant, since it has two velocity peaks. 
bioRxiv preprint doi: https://doi org/10.1101/143313; this version posted May 28,2017 . The copyright holder for this preprint (which was
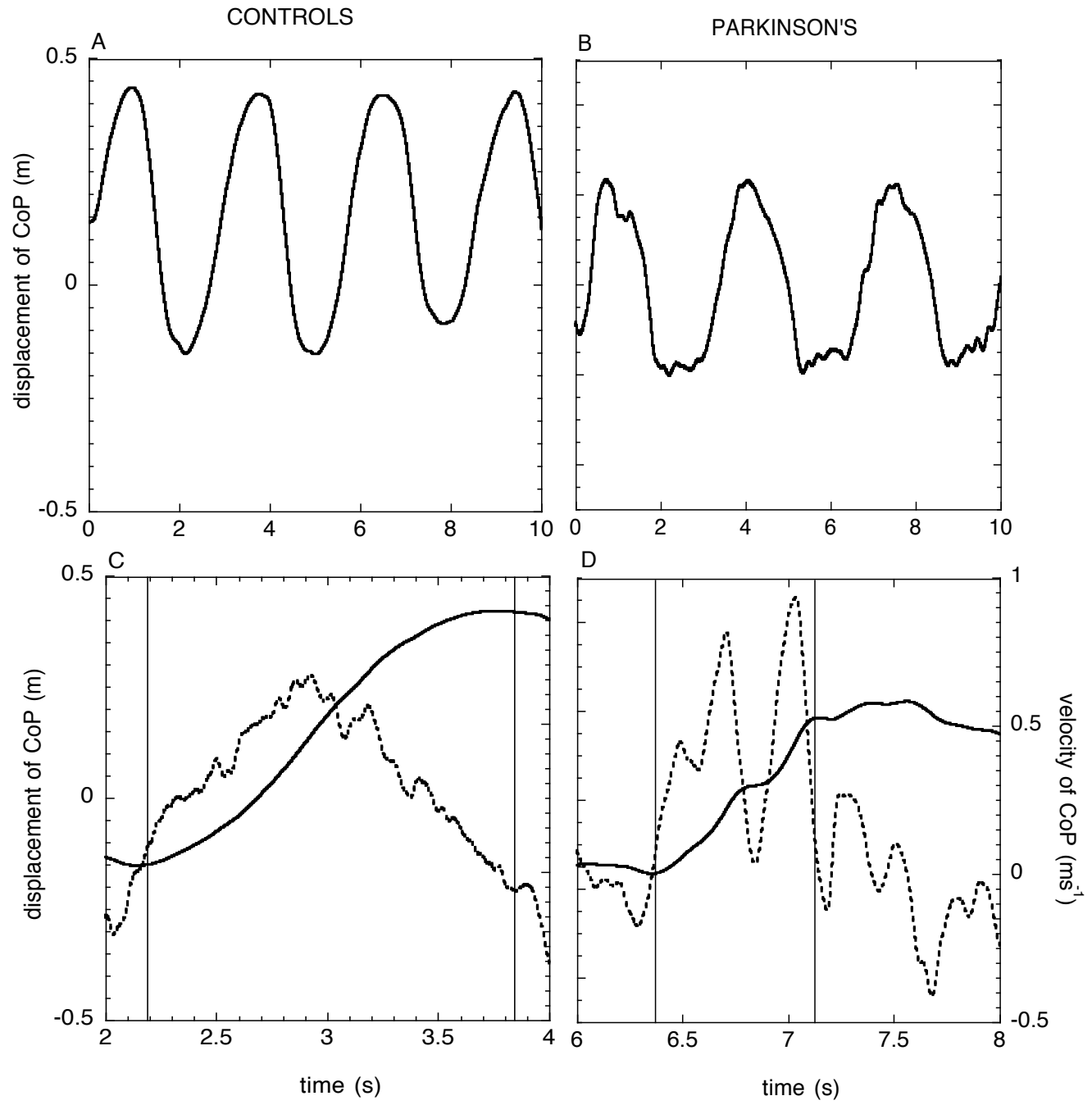

Fig. 2. Movement of centre of pressure (CoP) when swaying side-to-side keeping feet down (Task1), in baseline condition C1. (A) Healthy participant (control), (B) age-matched Parkinson's participant. (C) and (D) zoomed-in portions of (A) and (B), as indicated on the time axes. The broken-lines graph the velocity of the $\mathrm{CoP}$. The vertical grey lines indicate the start and end points for the $\operatorname{tau} G$ analysis of the movement of the CoP to the participant's left. 
bioRxiv preprint doi: https://doi.org/10.1101/143313; this version posted May 28, 2017. The copyright holder for this preprint (which was not certified by peer review) is the author/funder, who has granted bioRxiv a license to display the preprint in perpetuity. It is made available under aCC-BY-ND 4.0 International license.
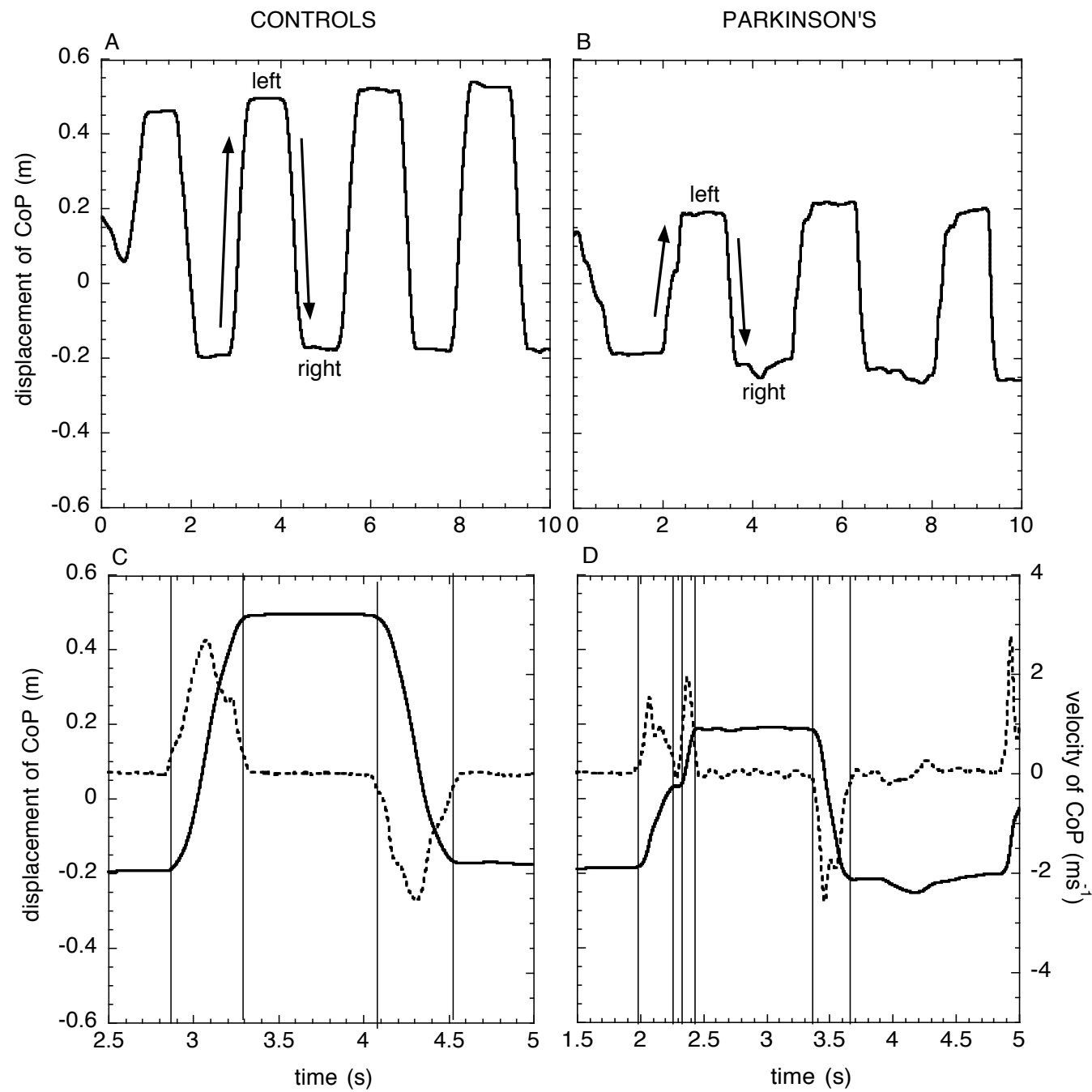

Fig. 3. Movement of centre of pressure (CoP) when swaying side-to-side lifting trailing foot (Task 2), in baseline condition C1L. (A) Healthy participant (control), (B) age-matched Parkinson participant. (C) and (D) zoomed-in portions of (A) and (B), as indicated on the time axes. Each show a rightward sway followed by a leftward sway. The broken-lines graph the velocity of the CoP. The vertical grey lines indicate the start and end points for the tau $G$ analysis of the displacement of the CoP. 
To assess the effects of practice turning the wheel with and without the whoop sounds, we first computed, from the movement of the centre of pressure of the feet on the force plates (Methods), two performance measures: \% tauG-coupled, the percentage of the sway data that fitted the $\operatorname{tau} G$ function to a criterion $r^{2}>0.95$; and $k$ of tauG-coupling, the $k$ value of the tauG coupled sway movements. Performance was measured over fourteen consecutive sways (seven to the left, seven to the right) for each participant and each experimental condition. The mean $\%$ tauG-coupled and the mean $\mathrm{k}$ values of the tauG-couplings over each set of fourteen sway movements were then calculated.

The means are plotted in Fig. 4 for Task1 and in Fig. 5 for Task2. T1 is the baseline test; T2 is the test after turning a handle without sound; T3 is second baseline test, taken about 2 weeks after T1 and T2; T4 is the test after turning the handle accompanied with whoop sounds. Participants are colour-coded.

Figs. 4A and 5A show that across the 4 tests the control participants were generally quite high and consistent in their \% tauG-coupling scores: average (sd) 89.55 (5.94) and 93.14 (3.41) for Task1 and Task2 respectively. In contrast, Figs. 4B and 5B show that the Parkinson's \% tauGcoupling scores were lower and less consistent: average (sd) $76.10(0.09)$ and 72.01 (18.24) for Task1 and Task2.

Figs. 4E and 5E show that across the 4 tests the control participants were generally low and consistent in their $\mathrm{k}$ of tauG coupling scores: average (sd) $0.43(0.09)$ and 0.33 ( 0.09$)$ for Task1 and Task2 respectively. In contrast, Figs. 4F and 5F show that the Parkinson's k of tauG-coupling scores tended to be higher and less consistent: average (sd) $0.48(0.14)$ and $0.46(0.10)$ for Task1 and Task 2 respectively. This indicates that the Parkinson's participants were generally slightly more abrupt in their movements than the control participants.

The smaller panels $(\mathrm{C}, \mathrm{D}, \mathrm{G}, \mathrm{H})$ in Figs. 4 and 5 plot the ratios of the mean scores on tests T2 and $\mathrm{T} 1$, and on tests $\mathrm{T} 4$ and $\mathrm{T} 3$. The ratios $\mathrm{T} 2 / \mathrm{T} 1$ and $\mathrm{T} 4 / \mathrm{T} 3$ equal the ratio improvements in score after turning the handle without or with whoop sounds, respectively. In the case of $\mathrm{k}$ of tauGcontrol, the ratios plotted are the reciprocals of T2/T1 and T4/T3, because a less abrupt (lower k) movement represents an improvement. Thus, in general, a graph line up to the right indicates there was a greater ratio improvement following handle-turning with whoop sounds compared to without sounds. 

available under aCC-BY-ND 4.0 International license.

Table 3 shows that the number of participants (out of five) who showed greater ratio improvement following practice with whoop sounds compared to practice without sounds was generally higher for the Parkinson's participants, for whom the number was 4 or 5 . 
bioRxiv preprint doi: https://doi org/10.1101/143313; this version posted May 28, 2017. The copyright holder for this preprint (which was not certified by peer review) is the author/funder, who has granted bioRxiv a license to display the preprint in perpetuity. It is made available under aCC-BY-ND 4.0 International license.
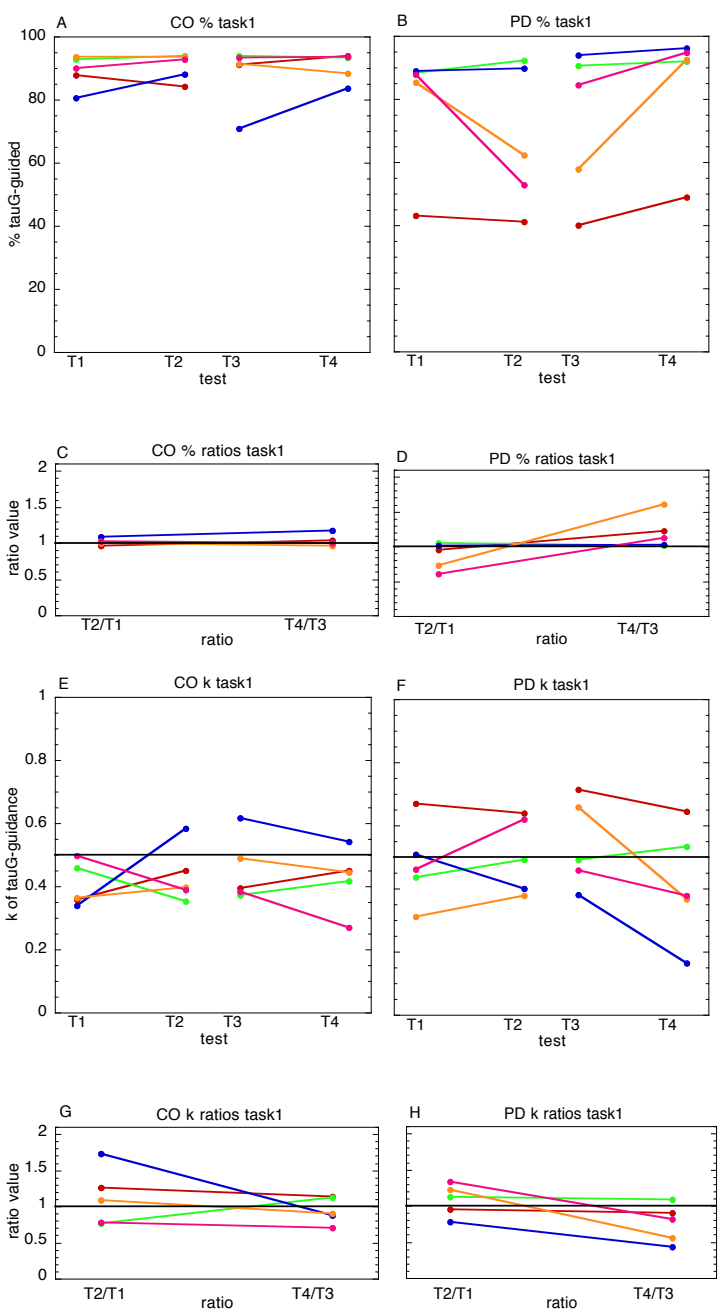

Fig. 4. 

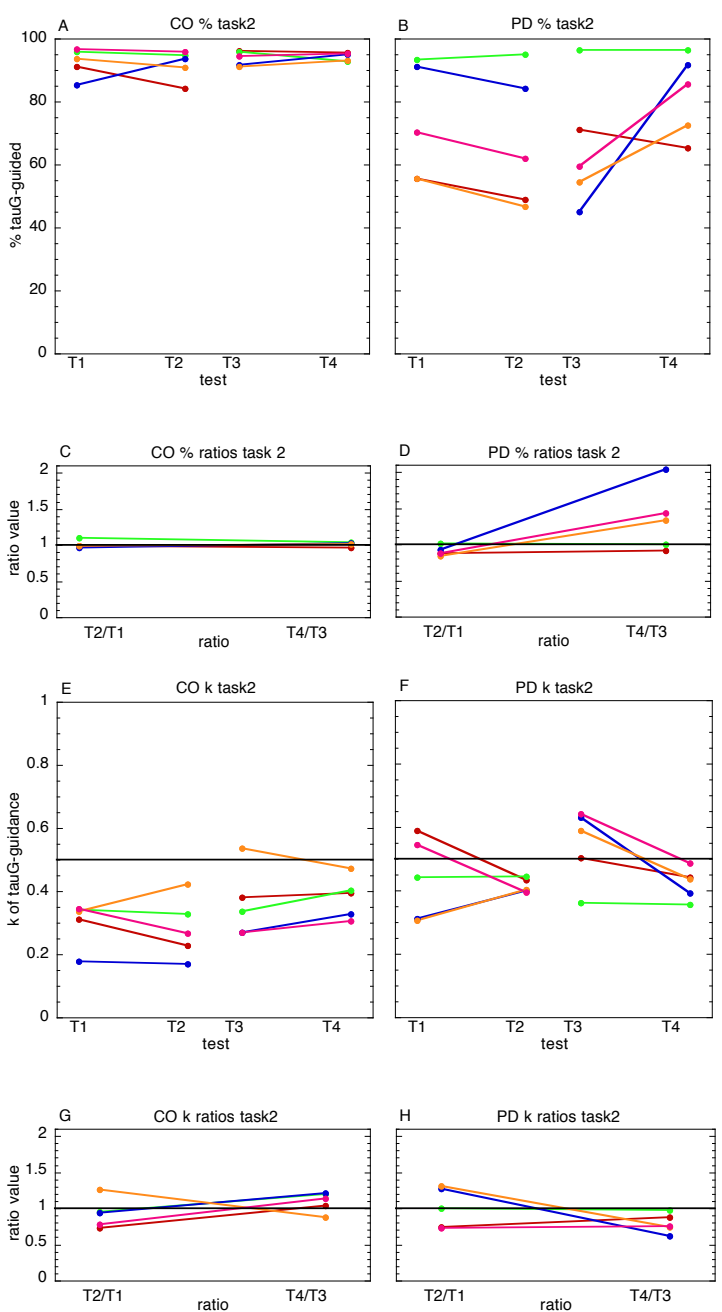

Fig. 5

\begin{tabular}{|l|l|l|l|l|}
\hline & Task1 & Task1 & Task2 & Task2 \\
\hline & CO & PD & CO & PD \\
\hline \% tauG-coupling & 2 & 4 & 3 & 4 \\
\hline k tauG-coupling & 4 & 5 & 1 & 4 \\
\hline
\end{tabular}

Table 3. Number of participants out of five who showed greater ratio improvement following practice with whoop sounds compared to without sounds. 


\section{DISCUSSION}

A theory of action control (General Tau Theory) was applied to analyzing normal and abnormal movements in PD; and to designing and testing the efficacy of a sonic aid for PD. A central aspect of the theory, which is supported by experimental evidence across a variety of actions and species, is that the trajectories of competent skilled actions follow a particular temporal pattern, which is described by the mathematical function, tauG. TauG-control of actions is deficient in PD. Therefore, we designed a device that generates whoop-like sounds, where the fundamental frequency of the sound follows the tauG pattern. Our hypothesis was that by listening to these sounds the nervous system of someone with PD might be helped subsequently to self-generate tauG patterns in their nervous system, which might facilitate movement control in different situations. Five adults with PD, and five age-matched controls took part in the study. They each listened to the sounds under two conditions: (a) experimental - turning a handle for 5 minutes while the sounds were played (b) control - turning the handle without the sounds. Before and after each condition, the tauG-control of lateral body sway while standing was measured, using force-plates, on two tasks: (i) keeping the feet down, (ii) lifting the trailing foot. The number of participants out of five, who showed greater ratio improvement following practice with whoop sounds compared to without sounds, was, on each task, higher for the PDs than the age-matched controls (4 vs 2 or 3 ). Thus, for the PDs, listening to the tauG whoop-like sounds while performing one action (handle turning) improved subsequent tauG-control on a different task (body-swaying).

It therefore appears that someone with PD can benefit in the tauG-control of movement by being exposed to sensory stimulation with a strong tauG component. In our experiments we used a pure tauG sound (a 'whoop'), which appeared to stimulate the nervous system quite effectively, even with only 5 minutes exposure to the sounds. However, this might not be the most effective way of stimulating the nervous system with the tauG pattern. Another possibility is to use music, which often contains tauG-patterns (Schogler et al. 2008). Music has emotional impact too, of course. Also it can more pleasant than listening to a series of whoops! Therefore a possible way of improving on the whoops therapy would be to use music that contains a strong tauG element and which the person enjoys listening to. 
bioRxiv preprint doi: https://doi.org/10.1101/143313; this version posted May 28, 2017. The copyright holder for this preprint (which was

\section{References}

Assaiante C, Woollacott M, Amblard B (2000) Postural adjustments during gait initiation. J Mot Behav. 32:211-226

Austad H, van der Meer (2007) Prospective dynamic balance control in healthy children and adults. Exp Brain Res 181:289-295

Benecke R, Rothwell JC, Dick JPR, Day B, Marsden CD (1986)

Brown RG, Marsden CG (1988) Internal versus external cues and the control of attention in Parkinson's disease. Brain 111:323-345

Comella CL, Stebbins GT, Brown-Toms N, Goetz CG (1994) Physical therapy and Parkinson's disease: a controlled clinical trial. Neurology 44:376.

Craig CM, Lee DN (1999) Neonatal control of nutritive sucking pressure: evidence for an intrinsic tau-guide. Exp Br Res 124: 371-382.

Craig CM, Delay D, Grealy MA, Lee DN (2000a) Guiding the swing in golf putting. Nature 405:295-296

Craig CM, Grealy MA \& Lee DN (2000b) Detecting motor abnormalities in pre-term infants. Exp Br Res 131:359-365

Del Olmo, MF, Cudeiro, J. et al. (**)Temporal variability of gait in Parkinson disease: effects of a rehabilitation programme based on rhythmic sound cues in Parkinsonism and related disorders. 11:25-33

Eni GO (1998) Gait improvement in parkinsonism: the use of rhythmic music. Int J Res 11:272-4.

Fahn S (1996) Controversies in the therapy of Parkinson's disease. Adv Neurol 69: $477-486$

Frith CD, Bloxham CA, Carpenter KN (1986) Impairment in the learning and performance of a new manual skill in patients with Parkinson's disease. J Neurol Neurosurg Psychiatry 49:661-668

Georgiou N, Iansek R, Bradshaw JL, Phillips JG, Mattingley JB, Bradshaw JA (1993) An evaluation of the role of internal cues in the pathogenesis of Parkinsonian hypokinesia. Brain 116:1575-1587.

Glickstein, M \& Stein, J (1991) Paradoxical movement in Parkinson's disease. Trends Neurosci 14:480-482

Grealy MA, Craig CM \& Lee DN (1999) Evidence for on-line visual guidance during saccadic gaze shifts. Proc R Soc Lond B 266:1799-1804

Harrington DL, Haaland KY, Yeo RA, Marder E (1990) Procedural memory in Parkinson's disease: impaired motor but not visuoperceptual learning. J Clin Exp Neuropsychol 12:323-39

Jiang Y, Norman KE (2006) Effects of visual and auditory cues on gait initiation in people with Parkinsons's disease. Clin Rehab 20:36-49

Lee DN (1998) Guiding movement by coupling taus. Ecological Psychology 10: 221-250

Lee DN (2009) General Tau Theory: evolution to date. Special Issue: Landmarks in Perception. Perception 38:837-858

Lee DN (2005) Tau in action in development. In Action as an Organizer of Learning and Development ed. Rieser JJ, Lockman J, Nelson CA, pp. 3-49. Erlbaum, Hillsdale, N.J.

Lee DN, Craig CM, Grealy MA (1999) Sensory and intrinsic coordination of movement. Proc R Soc Lond B 266:2029-2035 
bioRxiv preprint doi: https://doi.org/10.1101/143313; this version posted May 28, 2017. The copyright holder for this preprint (which was not certified by peer review) is the author/funder, who has granted bioRxiv a license to display the preprint in perpetuity. It is made available under aCC-BY-ND 4.0 International license.

Lee DN, Georgopoulos AP, Clark MJ, Craig CM, Port NL (2001) Guiding contact by coupling the taus of gaps. Exp Br Res 139:151-159

Majsak MJ, Kaminski T, Gentile AM, Flanagan JR (1998) The reaching movements of patients with Parkinson's disease under self-determined maximal speed and visually cued conditions. Brain 121:755-766

Majsak MJ, Kaminski T, Gentile AM, Flanagan JR (1998) The reaching movements of patients with Parkinson's disease under self-determined maximal speed and visually cued conditions. Brain 121:755-76

Marsden CD (1994). Parkinson's disease. Journal of Neurology, Neurosurgery and Psychiatry 57:672-681

Martin JP (1967) The basal ganglia and posture. Pitman, London

Morris ME, Iansek R (1996) Characteristics of motor disturbance in Parkinson's disease and strategies for rehabilitation. Human Movement Science 15:649-669

Morris M, Iansek R, Matyas T, Summers J (1996) Stride length regulation in Parkinson's disease: Normalization strategies and underlying mechanisms. Brain 119:551-568

Pacchetti C, Mancini F, Aglieri R, Fundaro C, Matignoni E, Nappi G (2000) Active music therapy in Parkinson's disease: An integrative method for motor and emotional rehabilitation. Psychosomatic Medicine 62:386-393

Pachetti C, Aglieri R, Mancini F, Martignoni E,Nappi G. (1998) Active Music Therapy and Parkinsons' Disease. Functional Neurology 13:57-67

Padfield GD, Lee D, Bradley R (2003) How do pilots know when to stop, turn or pull up? Developing guidelines for vision aids. J. American Helicopter Society 48:108-119

Schogler B, Pepping G-J, Lee, DN (2008) TauG-guidance of transients in expressive musical performance. Exp Br Res, 198:361-372

Soliveri P, Brown RG, Jahanshahi M, Caraceni T, Marsden CD (1997) Learning manual pursuit tracking skills in patients with Parkinson's disease. Brain 120:1325-37

Stallibrass C, Sissons P, Chalmers C (2002) Randomised controlled trial of the Alexander Technique for idiopathic Parkinson's disease. Clin Rehab 16:705-718

Platz T, Brown RG, Marsden CD (1988) Training improves the speed of aimed movements in Parkinson's disease. Brain 121:505-514

Thaut MH (1997) Rhythmic auditory stimulation in rehabilitation of movement disorders: a review of current research. In: Schneck DJ, Schneck JK (eds) Music in Human Adaptation. MMB Music: St Louis MO

Thaut MH, Kenyon GP, Schauer ML, McIntosh GC (1999) The connection between rhythmicity and brain function. IEEE Engineering in Medicine and Biology 18:193-200

Thaut MH, McIntosh GC, Rice RR (1997a) Rhythmic facilitation of gait training in hemiparetic stroke rehabilitation. Journal of Neurological Sciences 151:207-212

Thaut MH, Miller RA, Schauer M (1997b) Rhythm in human motor control: adaptive mechanisms in movement synchronization. In: Sneck DJ, Schneck JK (eds) Music in Human Adaptation. MMB Music: St LouisMO

Van Wegen E, Lim I, de Goede C, Nieuwboer A, Willems A, Jones D, Rochester L, Hetherington V, Wolters EC, Kwakkel G (2006) The effects of visual rhythms and optic flow on stride patterns of patients with Parkinson's Disease. Parkins Rel Dis 12: 21-27 
bioRxiv preprint doi: https://doi.org/10.1101/143313; this version posted May 28, 2017. The copyright holder for this preprint (which was not certified by peer review) is the author/funder, who has granted bioRxiv a license to display the preprint in perpetuity. It is made available under aCC-BY-ND 4.0 International license. 